\title{
Managerial Approaches of Selected Government Executives to Basic Communication on the Job
}

\section{Emmie T. Ribaya}

Master of Arts in Public Administration, Rizal Technological University, Mandaluyong City, Metro Manila, Philippines

\section{Abstract}

The study aims to determine the approaches of selected government executives to basic communication on the job, specifically their level of confidence and assertiveness in communication skills which are essentials for good leadership. The paper also seeks to correlate the executives' communication skills to intellective and nonintellective variables. A descriptive method of research was employed and no sampling

Corresponding Author: Emmie T. Ribaya ana_ribaya@yahoo.com

Received: 23 April 2018 Accepted: 8 May 2018

Published: 4 June 2018

Publishing services provided by Knowledge $\mathrm{E}$

(c) Emmie T. Ribaya. This article is distributed under the terms of the Creative Commons

Attribution License, which permits unrestricted use and redistribution provided that the original author and source are credited.

Selection and Peer-review under the responsibility of the IRCHE 2017 Conference Committee. scheme was utilized because the whole population consisting of ninety-seven middle managers was used as respondents and purposively selected from Department of Finance (DOF), Department of Transportation and Communication (DOTC), Department of Labor and Employment (DOLE) and Department of Interior and Local Government (DILG). Findings revealed that most of the respondents are aged 36-45 years old, female, bachelor's degree holders, married and rendered 11-15 years of service in their respective government agencies.

Results manifested that the respondents are highly effective in their technical skills, moderately effective in their interpersonal skills, and highly effective in their conceptual skills. When grouped by variables, the respondents are overall moderately effective in their managerial skills, and the overall level of confidence and assertiveness of the respondents in their approaches to basic communication on the job in all managerial skills is less confident and assertive regardless of variables.

Data disclosed that there is no significant correlation between the respondents' managerial skills and level of confidence and assertiveness when grouped according to variables. Therefore, there is also no significant correlation of the respondents' overall level of confidence and assertiveness when grouped according to variables.

Keywords: Government Executives, Managerial Skills, Confidence, Assertiveness, and Communication 


\section{Introduction}

Managers need to recognize that managing is a skill quite different from other kinds of work which requires a special set of skills and abilities. These are developed by gaining an understanding of the principles of management and then applying them to practical situations.

Managerial styles and skills are critically important to enhance relations with the subordinates and thereby achieve the goals of increased effectiveness, efficiency, and satisfaction in the workplace. It is in this understanding that competence in communication is necessary and an important approach to become an effective manager.

Leading, motivating, and team building are related activities used by managers accomplished to some extent through communicating with organization members according to Certo (2013) [1]. For example, managers decide what kind of leaders they should be after analyzing the characteristics of various groups with which they will interact and how these groups can be most motivated. Then, regardless of the strategy they adopt, their leading, motivating, and working with groups will be accomplished, at least to some extent, by communicating with other organization members.

Essentially all management activities are at least partially accomplished through communication or communication-related endeavors. Since communication is used repeatedly by managers, communication skill is often referred to as the fundamental management skill.

A manager who desires to assign the performance of a certain task to a subordinate would use the communication process in the following way. First, the managers would determine exactly what task he wanted the subordinate to perform. Then the manager would encode and transmit a message to the subordinate that would accurately reflect this assignment. The message transmission itself could be as simple as the manager telling the subordinate what new responsibilities include. Next, the subordinate would decode the message transmitted by the manager to ascertain its meaning and then respond to it as he thinks appropriate.

In any undertaking where people are involved, communication skills are needed to convey messages. In education, be it in schools or administrative offices, communication takes on even greater significance because the product is essentially a service and the recipients of the service are impressionable students. As imparted by Sweeney and Stoops (1981) [2], office employees need sophisticated communication skills. They must be aware of how communication transcends the fundamentals of talking and listening. They must understand that communication can be transmitted by 
words, nonverbal messages, emotions, and symbols. Office members should be skillful in assertive techniques so they can proficiently deal with situations that could cause problems and handle them in such a way that the other person feels his needs are being met. Furthermore, we must keep in mind that communication includes words, listening, self-esteem, self-disclosure and feelings in order to facilitate a smooth operating office.

Communicative competence as explained by Fisher (1994) [3] is more than simply having a style of communicating. Seemingly, everyone has a communicative style. Competence is adopting that particular style so that it is appropriate to the communicative situation. The greater the variety of communicative situations you have experienced, the more likely you are to judge what communicative behaviors (or style) are appropriate. In terms of your communicative style, adaptability is a dimension of communicative competence.

If managers discover that their communication effectiveness is relatively low over an extended period of time, they should assess their situation to determine how to improve their communication skill.

Considering the above discussions on communication skill related to management style, this research paper deems it wise to test the expertise of managers in asking smart questions, a communication-related tool oftentimes not given a heed.

\section{Objectives of the Study}

Specifically, answers to the following sub-problems are sought:

1. How well do the executives handle the given situations classified to managerial skills when grouped according to variables in terms of technical skills, interpersonal skills, and conceptual skills?

2. What level of confidence and assertiveness do executives generally apply when handling the above situations regardless of variables?

3. Is there any significant relationship between the skills and level of confidence and assertiveness of the selected government executives when grouped according to variables?

Lastly, the alternative hypothesis tested by the researcher was "There is a significant relationship between the skills and level of confidence and assertiveness of selected government executives when grouped according to variables." 


\section{Theoretical/Conceptual Framework}

The communication activities of managers generally take place within an organization and involve sharing information with other organization members. In fact, Leveriza (2005) [4] expressed that communication is the life-blood of an organization because it plays a major role in realizing goals of the organization.

According to Certo (2013) [1], these activities are carried out through the interpersonal communication process in which the source determines what information he or she intends to share; encodes this information in the form of a message; then transmits the message as a signal to the destination. The destination decodes the transmitted message to determine its meaning and then responds accordingly. Furthermore, Fisher (1994) [3] points out that the competence or skill in interpersonal communication is easier to recognize than to define. But probably there is difficulty in defining precisely what makes them competent. Wiemann, et al. (2012) [5] reiterate that interpersonal competence then becomes more a matter of avoiding errors or traps that lead to relational suffering (or deadlock) than of getting things just right communicatively. The relationship is the context in which communication takes place (and in which meaning emerges).

Leeds (1987) [6] theorized that one of the most productive, positive, and helpful skills a manager can use to improve his communications approach as well as his management style is asking skilled questions. Through the process of asking questions, we will experience undergoing personal evaluation that requires "brutal honesty" to be able to get the best information about our approaches to different business situations. Furthermore, Leeds also conceptualized that learning to question yourself is as valuable as being able to ask smart questions to others, thus developing our managerial style as well as our confidence and assertiveness in communication.

The theories and concepts presented constituted the framework from which this research is anchored. They provided insights and understanding about the relationship of managerial skills to basic communicative approaches on the job.

\subsection{Research paradigm}

Figure 1 shows the flow on how the intellective and non-intellective variables are treated in the study to reveal the desired results. 


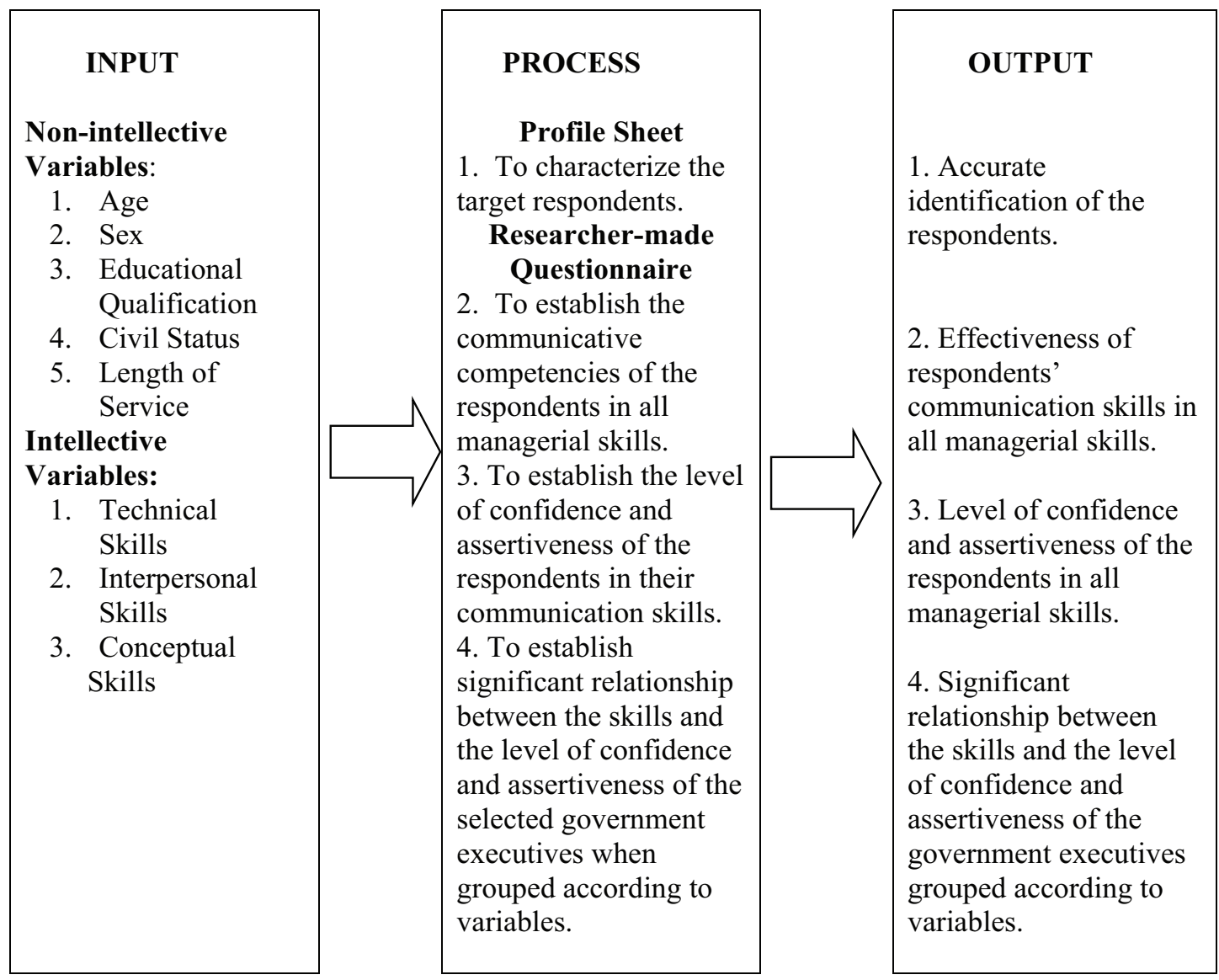

Figure 1

\section{Materials and Methods}

This study is confined to the executives of the Department of Finance, Department of Labor and Employment, Department of Transportation and Communication, and Department of Interior and Local Government. These officers were receiving wages within Salary Grades 18 to 24 . The identified government agencies were randomly picked by the researcher. Respondents categorically came from the different departments or units of the government agencies, namely: administrative service, financial and management service, human resource development service, planning service, and legal service.

Specifically, this thesis purports to acquire knowledge and understanding on the accosting ability of respondents using Leed's modified model of Smart Questions.

Consequently, the analysis of their responses are emphasized pondering on the respondent's communicative approaches to basic communication on the job.

Interpretations of answers are restricted to the perception of the respondents and reviewed comprehensively for the purpose of gaining information and commitment 
among administrative officers on their careers. Objectivity is practiced to the utmost, despite inherent research and human limitations.

Interpretation of problems that need ranking and scoring was made by assigning numerical values of $4,3,2$, and 1 with verbal explanation, as follows:

$3.21-4.00$ - highly effective

$2.41-3.20$ - moderately effective

$1.61-2.40$ - less effective

$0.81-1.60$ - least effective

$0.00-0.80$ - ineffective

With regards to problems number 2 and 3 , where scoring ranging from 1 to 125 , the following verbal interpretations were used:

101 - 125 - highly self-confident

and assertive

91 - 100 - moderately self-confident

and assertive

75 - 90 - less self-confident and

assertive

Less than 75 - least self-confident and

assertive

A researcher-modified questionnaire using the model of Leed's "Smart Questions" with Personal Data Sheet was employed in the collection of data. The said instrument was moderately modified by the researcher with the help of soliciting judgment from local executives who are authorities in organizational management to suit the "pinoy" style in communication. This modified questionnaire was utilized in gathering data on manager's communicative approaches to difficult business situations using intellective and non-intellective variables. For statistical treatment, the Pearson - Product Moment Correlation was employed to find the magnitude and direction of relationships.

The application of results of this research was limited to the people involved in the proceedings of this work and specifically to the four selected government agencies where they are connected. However, other agencies may adopt the output as long as it applies and answers their needs.

A descriptive method of research was employed and no sampling scheme was utilized because $100 \%$ of the whole population consisting of ninety-seven middle managers was used as respondents. They are purposively selected from Department 
of Finance (DOF), Department of Transportation and Communication (DOTC), Department of Labor and Employment (DOLE) and Department of Interior and Local Government (DILG). Through the Personal Data Sheet, the respondents' profile was identified: majority of the executives are aged $36-45$ years old which is $52.4 \%$ of the total population, and the dominant sexual classification is female (63.5\%). The sheets collected manifested that most of the executives are bachelor's degree holders (50.8\%) and are married (68.3\%). It was also revealed that most of the executives have rendered 11-15 years of service $(34.9 \%)$ in their respective government agencies.

\section{Results and Discusion}

\section{With regards to how well do the executives handle the business situations classified as to managerial skills when grouped according to variables:}

TABLE 1: Technical Skills of the Respondents According to Age G
\begin{tabular}{|l|c|c|c|c|}
\hline Age Group & N & Mean & Verbal Interpretation \\
\hline $26-35$ years old & 15 & 3.33 & Highly effective \\
\hline $36-45$ years old & 33 & 3.36 & Highly effective \\
\hline $\begin{array}{l}46-55 \text { years old } \\
\text { 56 years old and above }\end{array}$ & $\mathbf{9}$ & 3.31 & 3.23 & Highly effective \\
\hline Average & $\mathbf{6 3}$ & $\mathbf{3 . 3 0}$ & Highly effective \\
\hline
\end{tabular}

Table 1 shows that respondents in all age brackets are highly effective in their technical skills regardless of age group as gleaned by an average mean score of 3.30.

This data reveal that to become an executive, age is not a big factor. What is basic is that they have completed the standard years of appropriate formal education and mature enough to take responsibility. As studied by Morreale, Osborn and Pearson (2004) [9], as individuals mature and become working adults, communication competence continues to be essential. Employers identify communication as one of the basic competencies every graduate should have, asserting that the ability to communicate is valuable for obtaining employment and maintaining successful job performance through working with groups and teams, with persons of diverse background, and when engaged in problem solving and conflict management.

Table 2 shows that all respondents regardless of sex are highly effective in their technical skills as gleaned by an average mean score of 3.31 .

The result manifests that sex is not an element when executives exchange information to form objectives and set course of action for the operation of the organization. 
TABLE 2: Technical Skills of the Respondents According to Sex.

\begin{tabular}{l|l|l|l|l|} 
Sex & N & Mean Verbal Interpretation \\
\hline Male & 23 & 3.22 & Highly effective \\
\hline Female & 40 & 3.40 & Highly effective \\
\hline Average & 63 & 3.31 & Highly effective \\
\hline
\end{tabular}

TABLE 3: Technical Skills of the Respondents According to Educational Attainment.

\begin{tabular}{|l|c|c|c|c|}
\hline Educational Attainment & N & Mean & Verbal Interpretation \\
\hline Bachelor's Degree & 32 & 3.35 & Highly effective \\
\hline Bachelor's Degree with masteral units & 14 & 3.30 & Highly effective \\
\hline Master's Degree & 13 & 3.32 & Highly effective \\
\hline Master's Degree with doctoral units & 4 & 3.31 & Highly effective \\
\hline Average & $\mathbf{6 3}$ & $\mathbf{3 . 3 2}$ & Highly effective \\
\hline
\end{tabular}

Table 3 shows that the respondents, regardless of educational attainment, are highly effective in their technical skills as gleaned by an average mean score of 3.32 .

This result divulges that regardless of educational attainment, all respondents handle well the technical situation manifested in the questionnaire. As pointed by Mintzberg (1998) [14], the ability to communicate effectively which is one of the basic technical skills of a manager is considered very important. Morreale, Osborn and Pearson (2004) [9] reiterated that the communication discipline should be viewed as central on college campuses. Humans are born with the ability to vocalize but not with the knowledge, attitudes, and skills that define communication competence. The ability to communicate effectively and appropriately is learned and therefore must be taught, and this is supported by the fact that the medium of instruction here in the Philippines is English. It is not surprising then that the respondents are highly effective in their technical skills regardless of educational attainment.

TABle 4: Technical Skills of the Respondents According to Civil Status.

\begin{tabular}{l|l|l|l|l|} 
Civil Status & N & Mean & Verbal Interpretation \\
\hline Single & 18 & 3.25 & Highly effective \\
\hline Married & 43 & 3.37 & Highly effective \\
\hline Separated & $\mathbf{1}$ & 3.37 & Highly effective \\
\hline Widow/widower & $\mathbf{1}$ & 3.25 & Highly effective \\
\hline Average & $\mathbf{6 3}$ & $\mathbf{3 . 3 1}$ & Highly effective \\
\hline
\end{tabular}

Table 4 reveals that all respondents regardless of civil status are highly effective in their technical skills as gleaned by an average mean score of 3.31.. 
The result showed that civil status has no bearing on the effectiveness of executives in their approaches to basic communication on the job with regards to technical skills. The process of exchanging information to achieve common understanding between two or more people about work-related issues does not require executives to be single or married.

TABLE 5: Technical Skills of the Respondents According to Length of Service.

\begin{tabular}{l|l|l|l|l|}
\hline $\begin{array}{l}\text { Length of Service } \\
\text { 10 years and below }\end{array}$ & N & Mean & Verbal Interpretation \\
\hline $11-15$ years & 22 & 3.32 & Highly effective \\
\hline $16-20$ years & 13 & 3.42 & Highly effective \\
\hline $21-25$ years & 9 & 3.42 & Highly effective \\
\hline 26 years and above & 7 & 3.16 & Moderately effective \\
\hline Average & 63 & $\mathbf{3 . 3 2}$ & Highly effective \\
\hline
\end{tabular}

Table 5 discloses that in terms of length of service, majority of the respondents are highly effective in their approaches to basic communication on the job where their technical skills are concerned as gleaned by an average mean score of 3.32. Respondents with 26 years and above of service in the government are moderately effective in their approaches to basic communication with regards to their technical skills.

The highly effective and moderately effective interpretations of the result support that length of service does not affect the communication competency of a manager in handling technical situations.

TABLE 6: Interpersonal Skills of the Respondents According to Age Group.

\begin{tabular}{l|c|c|c|}
\hline Age Group & N & Mean & Verbal Interpretation \\
\hline $26-35$ years old & 15 & 2.77 & Moderately effective \\
\hline $36-45$ years old & 33 & 2.77 & Moderately effective \\
\hline $46-55$ years old & 9 & 2.52 & Moderately effective \\
\hline $\begin{array}{l}56 \text { years old and above } \\
\text { Average }\end{array}$ & $\mathbf{6 3}$ & $\mathbf{2 . 4 6}$ & Moderately effective \\
\hline Moderately effective
\end{tabular}

Table 6 shows that respondents in all age groups are moderately effective in their interpersonal skills with regards to their approaches to basic communication on the job as gleaned by an average mean score of 2.63 .

It can be inferred that no matter how old and young are the executives, they need interpersonal skills because they spend considerable time interacting with people both inside and outside the agency. Age does not affect the interpersonal skills of executives 
on how they communicate to establish harmonious relationships with their colleagues, with their subordinates as well as with other people outside the organization.

TABLE 7: Interpersonal Skills of the Respondents According to Sex.

\begin{tabular}{l|l|l|l|} 
Sex & N & Mean & Verbal Interpretation \\
Male & 23 & 2.59 & Moderately effective \\
\hline Female & 40 & 2.78 & Moderately effective \\
\hline Average & $\mathbf{6 3}$ & $\mathbf{2 . 6 8}$ & Moderately effective
\end{tabular}

Table 7 shows that both sexes are moderately effective in their interpersonal skills in relation with their approaches to basic communication on the job as gleaned by an average mean score of 2.68 .

On the basis of the data presented, executives need not be a male or female to become an effective communicator especially in relating with other people which is a major interpersonal skill. This finding gives the impression that authorities always give high marks to a high degree of self-confidence which is not true. In fact, one of the reasons why many people are careful to show a degree of modesty is that in many situations over-confidence is seen as a bad sign by those in authority, and with good reason. For example, as a professor, I was aware that over-confidence is as destructive of good performance as is under-confidence. If under-confidence leads to timidity, over-confidence promotes disorganize work. This position shows that competence cannot be measured by sex.

TABLE 8: Interpersonal Skills of the Respondents According to Educational Attainment.

\begin{tabular}{l|r|r|l|} 
Educational Attainment & N & Mean & Verbal Interpretation \\
\hline Bachelor's Degree & 32 & 2.71 & Moderately effective \\
\hline Bachelor's Degree with masteral units & 14 & 2.85 & Moderately effective \\
\hline Master's Degree & 13 & 2.60 & Moderately effective \\
\hline Master's Degree with doctoral units & 4 & 2.58 & Moderately effective \\
\hline Average & $\mathbf{6 3}$ & $\mathbf{2 . 6 8}$ & Moderately effective
\end{tabular}

Table 8 shows that regardless of educational attainment, all respondents of the study are moderately effective in their interpersonal skills in relation to their approaches to basic communication on the job as gleaned by an average mean score of 2.68 .

The findings manifest that communication competence can contribute to the individual's adjustment and participation in satisfying interpersonal relationships. According to Fisher (19914) [3], one's self concept is acquired through interaction with others, an interpersonal skill of a manager. The author further reiterated that in psychological 
terms, achieving self-actualization involves communication activities such as making contributions in groups, exerting influence over others, and using socially acceptable behavior. These information support the outcome of the study that the respondents being an executives are equipped with proper education especially in the discipline of communication because it was revealed that they are effective in their communication skills in carrying out their interpersonal skills. As mentioned by Aiex of ERIC Digest (2002) [15], the academic world prepares its students to communicate in today's increasingly global business world.

TABLE 9: Interpersonal Skills of the Respondents According to Civil Status.

\begin{tabular}{l|l|l|l|l} 
Civil Status & N & Mean & Verbal Interpretation \\
Single & 18 & 2.70 & Moderately effective \\
\hline Married & 43 & 2.72 & Moderately effective \\
\hline Separated & 1 & 2.67 & Moderately effective \\
Widow/widower & 1 & 2.44 & Moderately effective \\
\hline Average & 63 & $\mathbf{2 . 6 3}$ & Moderately effective
\end{tabular}

Table 9 shows that all of the 63 respondents are moderately effective in their approaches to basic communication with regards to their interpersonal skills regardless of civil status as gleaned by an average mean score of 2.63 .

This manifestation reveals that civil status does not affect the effectiveness of executives in communicating their interpersonal obligations on the job. Pettit et al (1997) [8] found out that communication dimensions with the greatest support as predictors were accuracy of information, desire for interaction, communication load, trust in superior, influence of superior, and communication satisfaction. The mentioned predictors were related to interpersonal skills of a manager and were the prevailing atmosphere in an organization. These instances can happen whether an executive is single, married, separated or a widow.

TABLE 10: Interpersonal Skills of the Respondents According to Length of Service.

\begin{tabular}{l|l|l|l|l}
\hline $\begin{array}{l}\text { Length of Service } \\
\text { 10 years and below }\end{array}$ & $\mathbf{N}$ & Mean & 2.80 & Merbal Interpretation \\
\hline $11-15$ years & 22 & 2.82 & Moderately effective \\
\hline $16-20$ years & 13 & 2.72 & Moderately effective \\
\hline $21-25$ years & 9 & 2.41 & Moderately effective \\
\hline 26 years and above & 7 & 2.57 & Moderately effective \\
\hline Average & 63 & $\mathbf{2 . 6 6}$ & Moderately effective \\
\hline
\end{tabular}


Table 10 shows that executives regardless of length of service are moderately effective in their interpersonal skills as gleaned by an average mean score of 2.66.

This finding divulges that our government executives kept themselves within bounds of proper interpersonal relationship, not extreme or excessive. Fisher (1994) [3] had constantly reiterated in his book that communication is a process, and relationship is a process. As people continue communicating, they continually define and redefine their relationship with each other. Hence, as people spend more time with each other and more relationally experienced, they change, and so do they become more comfortable with the pattern of interaction.

TABLE 11: Conceptual Skills of the Respondents According to Age Group.

\begin{tabular}{l|c|c|c|c|}
\hline Age Group & N & Mean & Verbal Interpretation \\
\hline $26-35$ years old & 15 & 3.36 & Highly effective \\
\hline $36-45$ years old & 33 & 3.27 & Highly effective \\
\hline $\begin{array}{l}\text { 46-55 years old } \\
\text { 56 years old and above }\end{array}$ & 9 & 3.31 & 3.10 & Moderately effective \\
\hline Average & 63 & $\mathbf{3 . 2 6}$ & Highly effective \\
\hline
\end{tabular}

Table 11 shows that the fifty-seven respondents regardless of age are highly effective in their communicative approaches on the job when their conceptual skills are concerned as gleaned by an average mean score of 3.26. Respondents within the age group 56 years old and above who are moderately effective in their communicative approaches as gleaned by a mean score of 3.10.

Results reveal that age does not affect the executives' approaches to basic communication on the job in the area of conceptual skills. Young managers nowadays are equipped with appropriate educational background and trainings making them capable of their roles. They are brutally honest and open on what's on their minds and their feelings. Technologies made our young executives more creative and aggressive to express what they are thinking as well as the senior executives who passed through stages of development where they begin to take important characteristics. This is true in our country where senior executives become aware of their roles in the workplace because as they mature, they become familiar with one another's strengths and weaknesses and are more secure in their role in the organization.

Based on the above information, it can be concluded that executives regardless of age allow them to think strategically, to see the "big picture," and to make broad-based decisions to serve the overall organization. 
TABLE 12: Conceptual Skills of the Respondents According to Sex.

\begin{tabular}{l|l|l|l|} 
Sex & N & Mean Verbal Interpretation \\
\hline Male & 23 & 3.07 & Moderately effective \\
\hline Female & 40 & 3.40 & Highly effective \\
\hline Average & 63 & $\mathbf{3 . 2 3}$ & Highly effective \\
\hline
\end{tabular}

Table 12 shows that female respondents are highly effective in their communicative approaches on the job with a mean of 3.40 compared to male respondents who are moderately effective as gleaned by a mean of 3.07.

The result showed that female executives are more articulate in communicating their ideas especially in decision-making. Generally, female managers are more meticulous and have more capacity to understand various cause-and-effect relationships in the organization, analyze how all the parts of the organization fit together, and to view the organization in a holistic manner.

TABLE 13: Conceptual Skills of the Respondents According to Educational Attainment.

\begin{tabular}{l|r|r|r|r|}
\hline Educational Attainment & N & Mean & Verbal Interpretation \\
\hline Bachelor's Degree & 32 & 3.32 & Highly effective \\
\hline Bachelor's Degree with master units & 14 & 3.29 & Highly effective \\
\hline Master's Degree & 13 & 3.29 & Highly effective \\
\hline Master's Degree with doctoral units & 4 & 2.94 & Moderately effective \\
\hline Average & $\mathbf{6 3}$ & $\mathbf{3 . 2 1}$ & Highly effective \\
\hline
\end{tabular}

Table 13 shows that respondents with bachelor's degrees, with masteral units and master's degrees are highly effective in their approaches to basic communication on the job with regards to their conceptual skills. While respondents with doctoral units are moderately effective in their communicative approaches in relation to their conceptual skills. Regardless of educational attainment, they are highly effective in their conceptual skills as gleaned by an average mean score of 3.21.

Fresh graduates executives are more effective in conceptual skills compared to senior executives. This fact maybe based on the current trend that clearly formal education is a prerequisite to business access. Graduates nowadays follow a welldeveloped program of study structured with new innovative approaches in learning making the new graduates become familiar with current research and thinking on management. Recent and future executives devote full-time energy and attention to learning. Some large companies have in-house training programs for furthering the education of managers which are usually offered for new executives. 
TABLE 14: Conceptual Skills of the Respondents According to Civil Status.

\begin{tabular}{l|c|c|c|} 
Civil Status & N & Mean & Verbal Interpretation \\
\hline Single & 18 & 3.32 & Highly effective \\
\hline Married & 43 & 3.27 & Highly effective \\
\hline Separated & 1 & 3.12 & Moderately effective \\
\hline Widow/widower & $\mathbf{1}$ & 3.25 & Highly effective \\
\hline Average & $\mathbf{6 3}$ & $\mathbf{3 . 2 4}$ & Highly effective \\
\hline
\end{tabular}

Table 14 shows that the respondents are highly effective in their communicative approaches if their conceptual skills are concerned as gleaned by an average mean score of 3.24. The remaining one respondent who is separated is moderately effective in his/her communicative approaches to basic communication on the job as per his/her conceptual skills are concerned.

The result implied that civil status does not have any relationship with an executive's competence in conceptual skills. This finding attests that executives regardless of civil status have almost the same level of effectiveness regarding ability to think in a wider perspective. Conceptual skills become proportionately more and more important at higher levels of the organization.

TABLE 15: Conceptual Skills of the Respondents According to Length of Service.

\begin{tabular}{l|l|l|l|l|}
\hline $\begin{array}{l}\text { Length of Service } \\
\text { 10 years and below }\end{array}$ & N & Mean & Verbal Interpretation \\
\hline $11-15$ years & 22 & 3.32 & Highly effective \\
\hline $16-20$ years & 13 & 3.17 & Moderately effective \\
\hline $21-25$ years & 9 & 3.31 & Highly effective \\
\hline 26 years and above & 7 & 3.20 & Moderately effective \\
\hline Average & 63 & $\mathbf{3 . 2 4}$ & Highly effective \\
\hline
\end{tabular}

Table 15 shows that respondents regardless of length of service are highly effective in their conceptual skills a gleaned by an average mean score of 3.24. Although respondents who rendered 16 - 20 years and with 26 years and above of service in the government are moderately effective in their conceptual skills.

Result indicates that to be on top-management position and to be effective, executives whether new or old-timers in their respective managerial position must also learn management skills through experience. By experiencing day-to-day pressures and by meeting a variety of managerial challenges, the individual develops insights that cannot be learned from a book. Effective managers learn their skills through a combination of education and experience. In an organization, neophyte executives 
engage in initial job experience and subsequently progresses through a variety of management situations. During the executives' rise in the organization, occasional education updates may supplement on-the-job experience. It is also a fact that natural ability, drive, and self-motivation also play roles in acquiring experience and developing management skills.

As to what level of confidence and assertiveness do executives generally apply when handling business situations regardless of variables:

Table 16 presents a brief account of the level of confidence and assertiveness of the respondents in their technical skills. For situation one, respondents are highly effective in handling a situation whenever they have been turned down for a raise as gleaned by a mean score of 3.24; however, DOTC and DILG executives showed that they are moderately effective in coping with an instance when they are turned down for a raise as gleaned by mean scores of 3.00 and 3.17 respectively. This shows that defensive and insecure people quit when they do not get what they want. Asking "What can I do to get a yes?' is the most productive kind of self-questioning.

For situation two, although the DOTC executives show that they are moderately effective in coping with a work overload as gleaned by a mean score of 3.17, commonly all respondents showed high effectiveness in handling the said situation as gleaned by a mean score 3.63. When a boss thoughtlessly piles an assignments, the best approach is setting priorities to help your boss establish focus and to help you work efficiently.

For situation three, DILG executives are moderately effective in handling the situation when their boss severely criticizes them as gleaned by a mean score of 3.13. However the prevalent result is that they are highly effective in handling the circumstance when they are criticized severely by their boss as gleaned by a mean score of 3.43. Waiting for the boss to cool down and asking how he would feel in a similar situation is helpful, especially if this behavior is a pattern that you would like to avoid in the future.

For situation four, mainly all respondents are moderately effective in handling the situation when they are being drafted to volunteer as gleaned by a mean score 2.97. We are all asked to do things we do not want to do, and asking the question "How important is this to you?" is the best answer because the response may effect your decision. If it is not particularly important, you may safely refuse; if the project is very important, you may gain extra points for doing it.

For situation five, all of the respondents are moderately effective in handling an instance when there is a sudden request that you move to a smaller office as gleaned 
by a mean score of 3.00. It is necessary that you stall for time to think about the best way to deal with this and ask them not to do anything until you can talk further.

For situation six, respondents are highly effective in showing strength in a group as gleaned by a mean score 3.60. Being well-prepared with questions and statements is obviously the best way to show strength in a group especially if it is your style to talk a lot.

For situation seven, DOLE respondents show that they are moderately effective in handling unsolicited advice as gleaned by a mean score of 3.18. Mainly all respondents are highly effective in handling unsolicited advice as gleaned by a mean score of 3.42 . When about to move to a new location and someone else sticks his nose in with advice, the best response is "Why are you sharing this with me?" The person may have valuable insight, but before you can evaluate his advice, you need to know his motivation.

For situation eight, DOLE respondents are moderately effective in recovering from a poor performance as gleaned by a mean score of 3.06. All in all respondents are highly effective in recovering from a poor performance as gleaned by a mean score 3.33. In this case, the very best thing to do is to ask a more experienced executive for constructive criticism. Not only will you get the help you need, but you will also develop that person's interest in you.

These results reveal that the selected government agency executives had a highly effective level of confidence and assertiveness in the area of technical skills as gleaned by a grand mean score of 3.33 .

Leveriza (1990) [4] emphasized that the government through its officials need to exert substantial effort in touching the lives of the people by cascading information about public service while determining people's needs, feelings and mindsets toward the organization. In relation to this, we cannot deny the fact that leaders are sometimes busy attending to their personal interests that they fail to focus on its work goals. The concept of Leveriza (1990) [4] was further substantiated by L.M. Applegate, J.I. Cash Jr., and D.Q. Mills of World Executive Digest (2003) [7] by revealing that as technology affects more aspects of the business, work itself will change and require a different set of skills. Managers need to be technically sophisticated and better educated in order to cope with the demands of technology in the workplace. Leaders must have creative powers in managing different on-the-job situations because they are the one who must decide when to use such technical skills and to what end. Workers nowadays are highly skilled and if not stimulated or their independence is threatened, they will go 
elsewhere. Furthermore, the authors reiterated that every job will be unique, people with different kinds of expertise will work on different sets of projects.

TABLE 16: Level of Confidence and Assertiveness in the Area of Technical Skills.

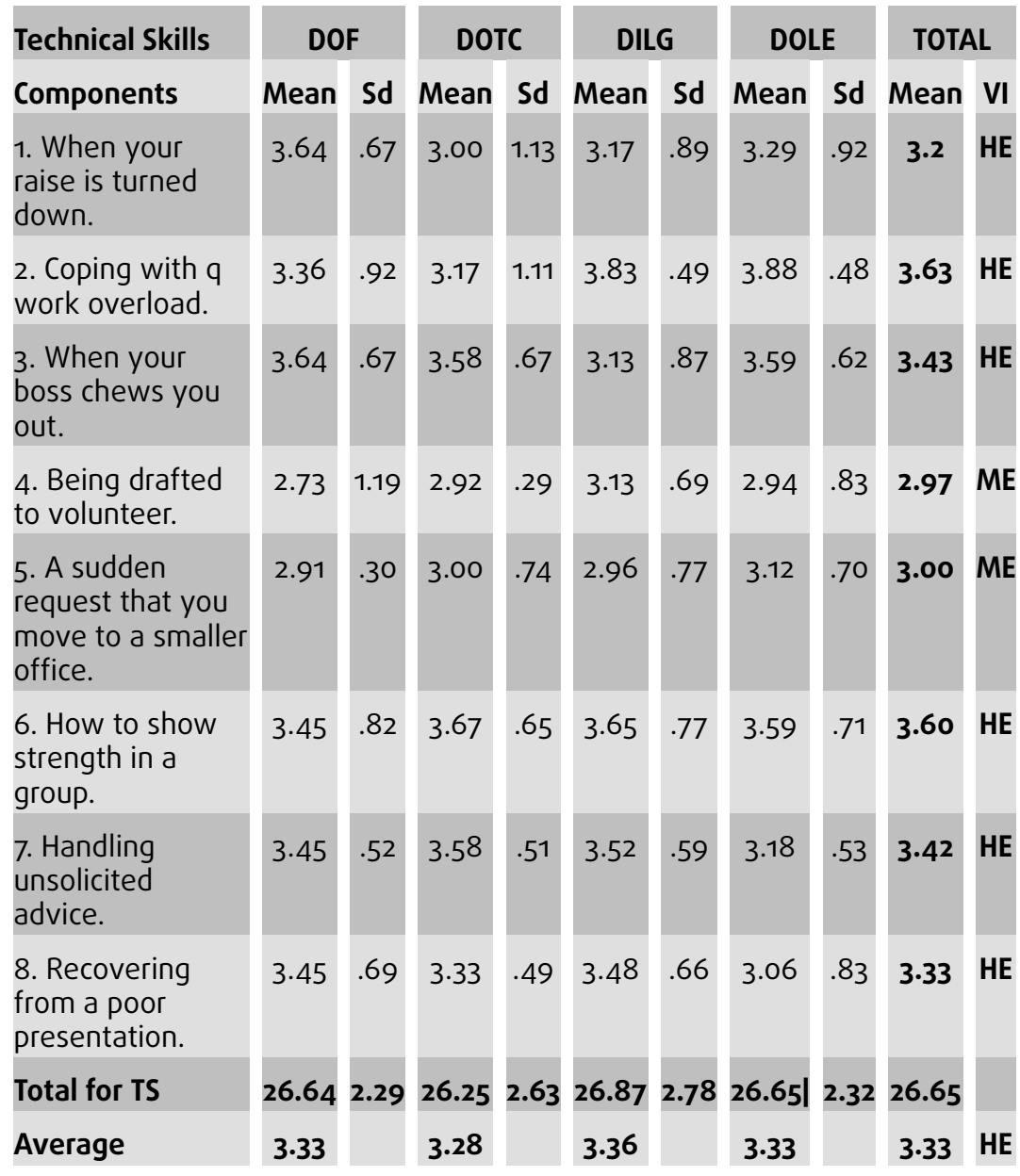

Table 17 discloses the summation of the level of confidence and assertiveness of selected government agency executives in the area of interpersonal skills. one, the common finding among the respondents is that they are moderately effective on how to get their phone call through as gleaned by a mean score of 2.42. This shows that they are also experiencing a hard time to get a commitment from someone to help them. However, DOTC and DOLE executives showed that they are less effective in getting their phone call through as gleaned by a mean scores of 2.08 and 2.23 respectively.

For situation two, generally all respondents are moderately effective in answering their boss' open-ended unexpected question as gleaned by a mean score of 3.16. This situation puts the receiver of the question on the spot, so it is better to have the necessary information needed to make a choice and avoid the risk of making a snap, possibly wrong, decision. DOF and DOLE respondents showed that they are highly 
effective in answering their boss' open-ended unexpected question as gleaned by a mean scores of 3.27 and 3.23 respectively.

For situation three, in meeting a new associates, it is best to ask questions and also volunteer a little bit about yourself without being asked. Executives from DILG revealed that they are moderately effective in connecting with newly introduced associate as gleaned by a mean score of 2.48 .

TABLE 17: Level of Confidence and Assertiveness in the Area of Interpersonal Skills.

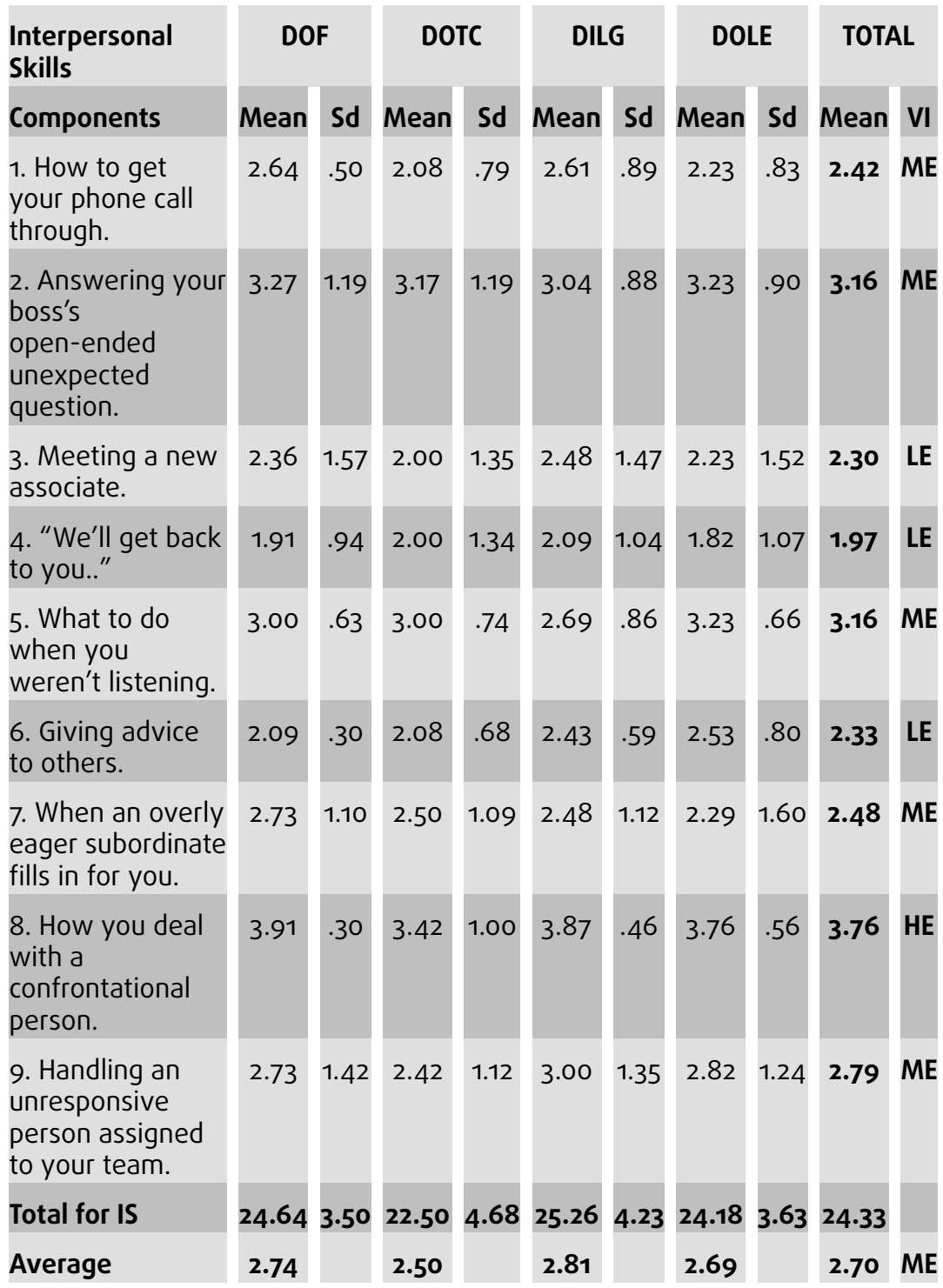

For situation four, all respondents are less effective in dealing with the circumstance when they are told after an interview, "We'll get back to you" as gleaned by a mean score of 1.97. Most of the time, when we encounter this kind of situation we want to be in control of the action, and we want to politely know when is the specific day and time to call for an answer. 
For situation five, the average answer of all respondents manifests that they are moderately effective in coping with the condition wherein at an important meeting the chairperson suddenly asks what one thinks of other person's point of view when the mind of the person asked was wandering and was not listening as gleaned by a mean score of 3.16. When we are caught off guard, requesting for further explanation or an application of the mentioned ideas is necessary because it gives us needed information to help us respond without revealing a lapse of attention on our part. But DOLE executives divulge that they are highly effective in coping up with the situation when they are asked and in fact, they are not listening as gleaned by a mean score of 3.23 .

For situation six, mainly all respondents are less effective in giving advice to others as gleaned by a mean score 2..33; however, DILG and DOLE executives are moderately effective in giving advice to others as gleaned by mean scores of 2.43 and 2.53 respectively. To be useful to the other person particularly if he is someone who is doing a job for you, knowing his objective will help in giving solutions to a problem.

For situation seven, commonly all respondents are moderately effective in dealing with an overly eager subordinate as gleaned by a mean score of 2.48 while DILG executives disclose that they are less effective in handling the said workplace situation as gleaned by a mean score of 2.29. Leeds suggest that dealing with a power-oriented employee requires a manager to give clear guidelines as to what he or she cannot do. A written statement of both responsibilities and extent of authority allows the manager to see whether his guidelines have been interpreted correctly.

For situation eight, respondents are highly effective in dealing with a confrontational person as gleaned by a mean score of 3.76. Respondents agreed that taking the offensive in some way is good strategy but asking for reason about the confrontational person's arguments is the best because this will lead to a more specific information why such discussion arises.

For situation nine, all respondents are moderately effective in handling an unresponsive person in their team as gleaned by a mean score of 2.79 . This shows that the respondents believe that starting a conversation about non-threatening topics will draw the person out.

The findings in Table 17 manifest that executives of the selected government agencies are moderately effective in their level of confidence and assertiveness in the area of interpersonal skills as gleaned by a grand mean score of 2.70 . This manifestation supports the outcome of a research study made by Pettit et al. (1997) [8] that their respondents supported communication dimensions such as accuracy of information, 
desire for interaction, communication load, trust in superior, influence of superior and communication satisfaction as the greatest moderator of the relationship between job performance and job satisfaction. Morreale, Osborn and Pearson (2002) [9] justified further that competence in communication can contribute to individuals' social adjustment and participation in satisfying interpersonal relationships. Executives who are not confident and assertive in their communication skills are sometimes viewed as less attractive by their peers and subordinates and enjoy fewer friendships. Antisocial and violent behavior often occur with underdeveloped social and conflict management skills. On the positive side, the ability to communicate supports sound psychological development. One's self concept is acquired through interaction with others. They explained that achieving self-actualization involves communication activities such as making contributions in groups, exerting influence over others and using socially acceptable behavior. Doyle (2013) [10] revealed that some leaders think they are great communicators, but actually they are not. A leader's perception of his effectiveness in communication may not be the same as to their subordinates' opinion. Therefore, it is the leader's primary responsibility not just to communicate but to communicate in such a way that he or she will be easily understood by his people to be able to achieve the goals of the organization. The latter further reiterated that the worldof-work nowadays is so intense that effective communication will make workers feel they belonged; thus, increase their morale, productivity and lessen turnovers.

Table 18 reveals the summarized level of confidence and assertiveness of selected government agency executives in the area of conceptual skills. For situation one, all respondents from the sample government agencies are highly effective in handling the blame for a department report as gleaned by a mean score 3.68.

For situation two, generally respondents are moderately effective in responding to criticisms directed at their department as gleaned by a mean score of 3.11; however, executives from DILG are highly effective in handling the said situation as gleaned by a mean score of 3.22 .

For situation three, all respondents are moderately effective in handling a business rejection as gleaned by a mean score of 2.92 .

For situation four, result reveals that mainly all respondents are highly effective in breaking the ice when dealing with a tough negotiator as gleaned by a mean score of 3.38 though executives from DOF are moderately effective in this particular situation as gleaned by a mean score of 3.09 .

For situation five, overall the respondents are highly effective in making a staffscheduling decisions as gleaned by a mean score of 3.68 although executives from 
TABLE 18: Level of Confidence and Assertiveness of the Respondents in the Area of Conceptual Skills.

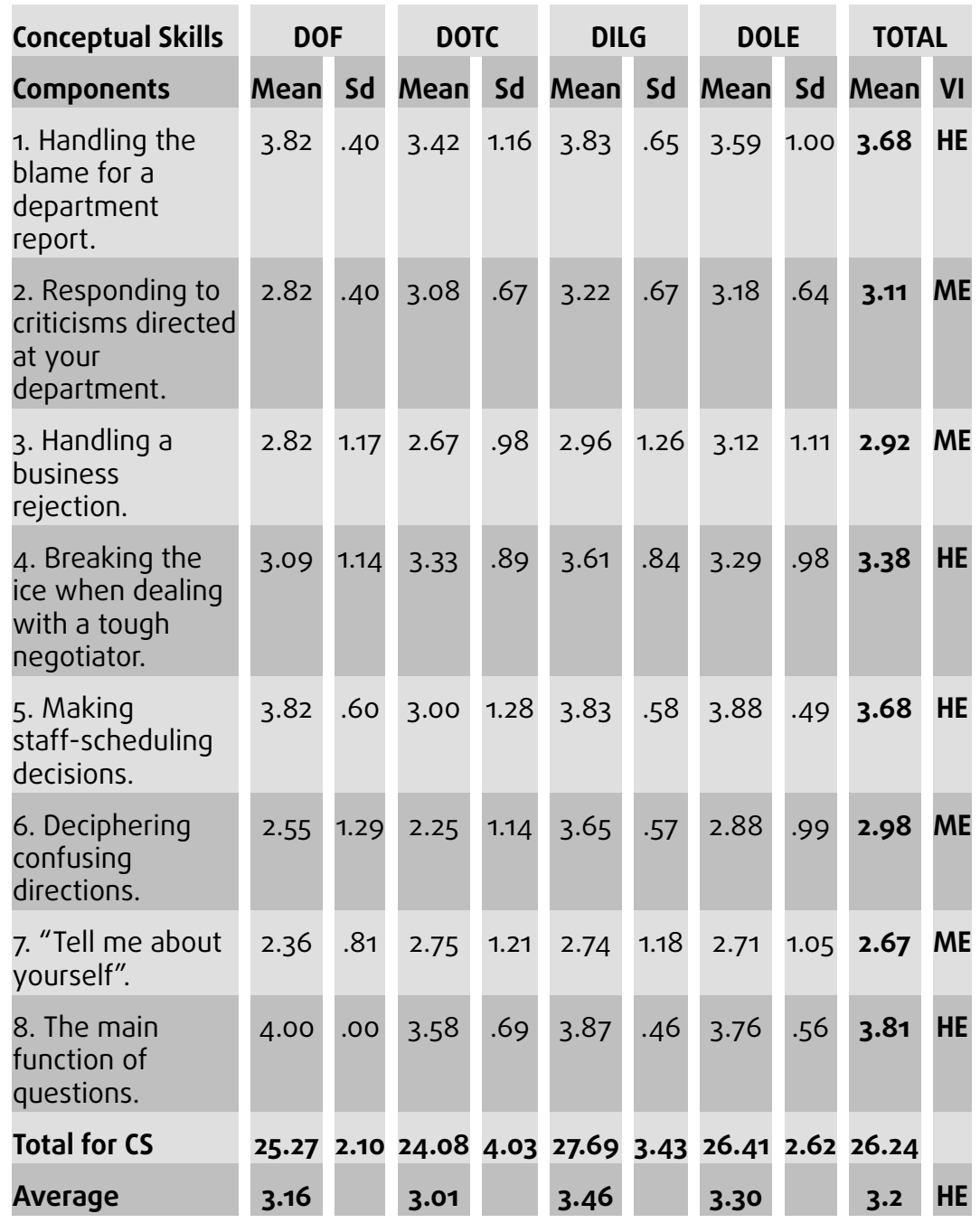

DOTC are moderately effective in staff-scheduling decision-making as gleaned by a mean score of 3.00 .

For situation six, commonly all respondents are moderately effective in deciphering confusing instructions as gleaned by a mean score of 2.98 .

Specifically, the result shows that executives from DOTC are less effective while executives from DILG are highly effective in dissecting confusing instructions.

For situation seven, all in all, the respondents are moderately effective in handling this awful question that people ask all the time: "Tell me about yourself." as gleaned by a mean score of 2.67; however, executives from DOF are less effective in this circumstance as gleaned by a mean score of 2.36 .

Lastly, for situation eight, all respondents are highly effective in knowing that the best use of questions is to gain information as gleaned by a mean score of 3.81 . 
These findings in Table 3 expose that respondents are highly effective in handling different organizational situations that require them to have adequate conceptual skills that will cultivate knowledge and the learning process in the organization, not just for productivity's sake but for the organization's success as gleaned by a grand mean score of 3.28. As revealed by D.G. Robinson of World Executive's Digest (2003) [11] in her article From Managing to Leading, leaders must adopt practices that encourage rapid and speedy response from workers to meet the challenges of the new decade. Decision making must be pushed down to the lowest level possible; employees must be "empowered" to act rather than have to seek permission to do so. Leaders must communicate any and all available information. Only with current information can employees make proper decisions. It was also reiterated by Leveriza (2008) [4] that communication can significantly improve the decision-making effectiveness of public administrators. Additionally, employees must be encouraged to go directly to a needed resource rather than work through the traditional chain-of-command; therefore, networking will be important.

As to the level of confidence and assertiveness the executives generally apply when handling the given business situations regardless of variables, Table 19 shows the summarized result of the level of confidence and assertiveness of selected government agency executives regardless of variables.

Executives from DOF, DILG and DOLE are less self-confident and assertive in their managerial skills regardless of variables as gleaned by total mean scores of 76.54 for DOF, 80.83 for DILG, and 77.24 for DOLE. For executives from DOTC, the result shows that they are least confident and assertive in their management skills as gleaned by a total mean score of 72.83 .

The table further revealed that the overall level of confidence and assertiveness of the selected government agency executives in their three types of managerial skills was less confident and assertive as gleaned by a total grand mean score of 76.85 .

As disclosed by Leeds (1987), managers with this altitude of confidence and assertiveness tend to blame circumstances and other people. Managers must realize that asking for help is not a sign of weakness. Asking questions will reduce anxiety, help avoid costly mistakes and let one develop a more people-oriented approach to one's career. DOTC executives who are least self-confident and assertive have to become more assertive for them to make it to the top. Being overworked and working under considerable stress reduces one's self-esteem. For self-improvement, a manager should avoid accepting the blame for foul-ups and refrain from giving-up too easily. Managers who lack confidence and assertiveness use to avoid confrontation 
TABLE 19: Overall Level of Confidence and Assertiveness of the Respondents in all Managerial Skills.

\begin{tabular}{l|c|c|c|c|c|}
\hline $\begin{array}{l}\text { Managerial Skills } \\
\text { Mean }\end{array}$ & DOF & DOTC & DILG & DOLE & TOTAL \\
\hline $\begin{array}{l}\text { Mean } \\
\text { 1. Technical Skills }\end{array}$ & 26.64 & 26.25 & 26.87 & 26.65 & 26.60 \\
$\begin{array}{l}\text { 2. Interpersonal } \\
\text { Skills }\end{array}$ & 24.63 & 22.50 & 26.26 & 24.18 & 24.39 \\
$\begin{array}{l}\text { 3. Conceptual } \\
\text { Skills }\end{array}$ & 25.27 & 24.08 & 27.69 & 26.41 & 25.86 \\
$\begin{array}{l}\text { Overall Total for } \\
\text { MS }\end{array}$ & $\mathbf{7 6 . 5 4}$ & $\mathbf{7 2 . 8 3}$ & 80.82 & $\mathbf{7 7 . 2 4}$ & $\mathbf{7 6 . 8 5}$ \\
\hline $\begin{array}{l}\text { Verbal } \\
\text { Interpretation }\end{array}$ & LesCA & LstCA & LesCA & LesCA & LesCA \\
\hline
\end{tabular}

at all costs. Inquiries about non-threatening situations will promote confidence and provide ways to affirm one's self without anxiety. This concept was supported by Brillantes (2003) [12] when he emphasized that creativity and innovations should emerged from the leaders. According to him there are several factors to consider, such as people's participation and support, media and information dissemination, support from external institutions, but the most important is leadership because it plays a key role in successful governance that facilitates, motivates and effects changes which are basically carried out through effective communication skills.

As emphasized by Santos (1999) [13], executives should realize that the communicating process is equally important between supervisor and supervisor, and between the supervisor and his boss. To be effective in communicating, executives or supervisors must realize the value of the free flow of information and establish a climate in which truthfulness and frankness can be possible between a subordinate and his superior.

Thus as emphasized by Morreale, Osborn and Pearson (2002) [9], researchers as well as educators attested to the vital role of communication in self-development. Competence in communication improves specific skills and abilities including critical thinking, media literacy and criticism and leadership skills. Executives are obliged to understand the importance of basic communication skills in the workplace and that acquiring communication knowledge allows one to gain personal power. The said authors support the findings of their colleagues who made a research on communicative competence that the most dramatic improvements in communication competencies were seen in four specific areas: feeling confident about oneself, feeling comfortable with perceptions of you, reasoning with people, and using language appropriately. 
This research was further substantiated by Mintzberg (1998) [14] by pointing out that a manager performs some of his most essential functions in his informational role. As a "monitor", he uses his outside contacts to scan the environment for information affecting the organization. As "disseminator." He distributes information from the outside or from higher up in the organization to his subordinates, or passes information from one subordinate to another. As "spokesman," he sends information to people outside his unit.

In fact, Doyle (2013) [10] revealed that researches found out that effective communication skills causes boosted morale, improved productivity, lessened turnover and harmonious working environment.

Finally, based on the gathered data, there is no significant correlation between the selected government executives' managerial skills when grouped according to variables. This outcome is manifested by the negative values of r, implying negative linear relationships between the variables and r values near or equal to 0 , implying a little or no linear relationships between variables used in the study as divulged in Table 20 below.

TABLE 20: Correlation of Executives' Managerial Skills Grouped According to Variables.

\begin{tabular}{l|ccc}
\multicolumn{4}{c}{ PEARSON R VALUES } \\
Variables & Conceptual Skills Mean Interpersonal Skills Mean & Technical Skills Mean \\
\hline Age & -.133 & -.230 & -.088 \\
\hline Sex & $.379\left(^{* *}\right)$ & .202 & $.278(*)$ \\
\hline Civil Status & -.072 & -.019 & .135 \\
\hline Educational Qualification & -.149 & -.087 & -.052 \\
\hline Length of Service & -.097 & $-.262\left(^{*}\right)$ & -.031 \\
\hline * Correlation is significant at the 0.05 level & & \\
** Correlation is significant at the 0.01 level & &
\end{tabular}

There is also no significant correlation of the executives' overall level of confidence and assertiveness grouped according to variables. The values showed no linear relationship from the paired variables as displayed in Table 21 below.

\section{Conclusion and Recommendation}

Based on the foregoing findings, the following conclusions were drawn: 
TABLE 21: Correlation of Executives' Level of Confidence and Assertiveness According to Variables.

\begin{tabular}{|c|c|}
\hline & PEARSON R VALUES \\
\hline Variables & Level of Confidence and Assertiveness \\
\hline Age & -.206 \\
\hline Sex & $.357\left(^{\star \star}\right)$ \\
\hline Civil Status & .009 \\
\hline Educational Qualification & -.123 \\
\hline Length of Service & -.190 \\
\hline \multicolumn{2}{|c|}{ * Correlation is significant at the 0.05 level } \\
\hline \multicolumn{2}{|c|}{ ** Correlation is significant at the 0.01 level } \\
\hline
\end{tabular}

1. Majority of the selected government executives are 36-45 years old, most of them are female, single in status, bachelor's degree holders, and have rendered 11-15 years of service in their respective government agencies.

2. In terms of managerial skills, the respondents are highly effective in their technical and conceptual skills, and moderately effective in their interpersonal roles regardless of variables.

3. The result showed that majority of the respondents are less confident and assertive in their managerial skills, and the remaining respondents are least confident and assertive; hence, the overall level of confidence and assertiveness of the selected government executives in all types of managerial skills is less effective.

4. The managerial skills and the level of confidence and assertiveness of the selected government executives are not affected by age, sex, educational qualification, civil status and length of service.

Based on the substance of the study, the researcher recommends the following ideas:

1. The non-intellective variables used by the researcher should not be prescribed as major requirements for a person to become a competent communicator though we cannot deny the fact that qualified and well-experienced individuals have more edge in obtaining employment and maintaining successful job performance.

2. Basically, government executives must realize that to become successful managers they should have technical, interpersonal and conceptual skills that vary as one progresses up in the organizational ladder. That is, he must combine education (formal coursework and continuing education) with a variety of experiences 
(training programs and previous jobs) to develop and refine his management skills.

3. People in managerial positions should always give high marks to a high degree of self-confidence and assertiveness in their communication skills, and the same time, cultivate knowledge and learning process in the organization by empowering the subordinates. In a globally competitive world, the government system should also make a difference by giving workers the power to speak and act rather than seek permission and just follow instructions to do so because these breed productivity and satisfaction among organizational members. But to empower subordinates, government executives must be self-confident and assertive enough to be tolerant of mistakes, must be willing to let go, and must stay out of the way and let the empowered subordinate get the credit.

4. A training program on building self-confidence and assertiveness in communicative approaches among government executives should be developed to prepare them further in carrying-out their responsibilities in advancing interests of the society and business, and in advancing careers.

5. More researches on related organizational communication should be undertaken to guide the academic world prepares its students to communicate in today's increasingly global business world. We should be aware that the technological advances reshaping our world at the dawn of the $21^{\text {st }}$ century will have powerful impact on organizational communication.

\section{References}

[1] Certo, Samuel C. (2013). Modern Management, $13^{\text {th }}$ Edition, Pearson Publishing.

[2] Sweeney, Carol R. and Stoops, Emery (1981). Handbook for Educational Secretaries and Office Personnel. U.S.A.: Allyn and Bacon, Inc., ISBN 0-205-07292-5.

[3] Fisher, B. Aubrey (1994). Interpersonal Communication: Pragmatics of Human Relationships. New York, U.S.A.: Random House, Inc.

[4] Leveriza, Jose P. (1990). Public Administration: The Business of Government, $2^{\text {nd }}$ Edition, National Book Store, ISBN 971-08-4694-9, pp.14-16.

[5] Wiemann, Mary, O'Hair, Dan, Mullin, Dorothy, and Teven, Jason (2012). Real Communication: An Introduction, $3^{\text {rd }}$ Edition, Belford/St. Martins, ISBN 9781457662928.

[6] Leeds, Dorothy (1987). Smart Questions, McGraw Hill Book. 
[7] World Executive's Digest. World Executive's Digest Inc., January 2003.

[8] Pettit, John D., Jr. (1997). "An Examination of Organizational Communication as a Moderator of the Relationship between Job Performance and Job Satisfaction." Journal of Business Communication, https://doi.org/10.1177/002194369703400105

[9] Morreale, Sherwyn P., Osborn, Michael M. and Pearson, Judy C (2002). "Why Communication is Important: A Rationale for the Centrality of a Discipline." National Communication Association, https://scholarworks.iu.edu/dspace/bitstream/2022/ 7015/2/umi-indiana-1080.pdf.txt

[10] Doyle, Shawn (2013). Jumpstart Your Leadership, Embassy Book Distributors, ISBN 13: 978-93-83359-05-9. pp. 49-70.

[11] World Executive's Digest. World Executive's Digest, Inc., December 2003.

[12] Brillantes, Alex B. (2003), Innovation and Excellence: Understanding Local Governance in the Philippines, National College of Public Administration and Governance, ISBN 971-8567-33-X, pp. 69-80.

[13] Santos, Emmanuel T. (1999). Organization and Management. Makati: International Academy of Management and Economics.

[14] Mintzberg, Henry (1998). The Nature of Managerial Work. New York, U.S.A.: Harper and Row.

[15] Aiex, Nola Kortner (2002). "Organizational Communication: Research and Practice." ERIC Digests, https://www.ericdigests.org/2002-4/communication.html. 